\title{
Integrating Sustainability Practices Using the Viable System Model
}

\author{
Allenna Leonard, Ph.D. \\ The Complementary Set* \\ 34 Palmerston Square \\ Toronto, Ontario M6G 2S7 \\ <allenna_leonard@yahoo.com>
}

\begin{abstract}
This paper represents an effort to explore the use of Stafford Beer's Viable System Model to design human communities that foster adaptation to criteria of sustainability in our natural and social environments. With the projected rise in sea level and other changes that may accompany warming temperatures, it seems probable that many communities, even some large cities, will have to be abandoned and their populations relocated. This difficult circumstance could create tens of millions of climate change refugees and be met with the failure and incompetence that characterized the response to Hurricane Katrina or it could provide an opportunity to rebuild in a manner that combines a high quality of life with a low impact on the environment.

Using the framework of the Viable System Model, three levels of recursion will be explored: the household, the neighborhood and the city. It will be possible to draw upon lessons learned about building and maintaining cities in different climates and under different conditions over the centuries and from the construction of 'new towns' in the past fifty years. It has been characteristic of communities that regularly endured environmental challenges to have fostered means of collaboration and cooperation to address them and to constrain competition within bounds that did not threaten their common survival. There is no shortage of ideas and designs that could be applied but there is not yet either the political and social infrastructure to integrate and implement them. Steps taken in this direction might help to coalesce the necessary political will.
\end{abstract}

The following are proposed as guidelines for design under the VSM.

The community and the city's external relationships with the surrounding natural, social and economic environments should be such that they can support themselves while avoiding endangering their own survival and well-being or that of their surrounding environments.

Their internal operations should be such that an adequate quality of life is available to everyone from the most dependent members of its society to the most productive.

They should pursue these ends with a view to maintaining a balance between collaboration/symbiosis and competition and with the fewest restrictions on the autonomy of members consistent with the other guidelines.

The Viable System Model can be both a template for design and a framework for discussion of what sustainable communities in a time of climate change might look like. Such discussions would be facilitated by Beer's Team Syntegrity process that he invented as a companion to the VSM. The process provides a whole system, high variety structure that gives equivalent status to each participant and 
viewpoint. This high level of communication will help to provide the cohesiveness that is needed when sacrifices must be made and hardship shared in order to achieve a new equilibrium with the environment.

Keywords: Viable System Model, sustainability, Team Syntegrity

\section{Introduction}

Human civilization in the 20th century entered a period of crisis serious enough to endanger its survival. Two major related factors are responsible for this condition. They are: environmental degradation, epitomized although not fully covered by the term 'climate change', and the wide and increasing gaps in the distribution of resources and opportunities, with its attendant threats of crime on the local level and war and terrorism at the national level. Separately and together, they call into question the viability of human life on this planet. If they are considered and acted upon separately, the threat to viability will remain severe. Only if they are addressed as a whole will the enterprise have a good chance of success.

There are three main challenges to taking this step. The first is our predominant way of thinking. Until a big picture, both/and, whole system perspective dominates our worldview; we will not be able to address our problems in a way that works for everyone. An 'us/them' or 'winners/losers' mentality is a luxury that humanity can only afford in small doses. No, this does not mean an end to competition. It does mean that it must be constrained within a context of collaboration. The second, which flows from the first, is the social and political will to make and deliver on a commitment to peace, justice, human rights and responsibility for the consequences of our actions that applies on a global scale. There is only a small minority in politics willing to take such positions and a smaller one still with the decision-making power to act on them. Progress in this arena requires the people to lead their governments. The third challenge, although it receives the most attention, is the scientific and technical one. Much knowledge is already in place here; many experiments have been proposed that could and should be performed; and there is no reason to suppose that more innovations will not be forthcoming.

Stafford Beer's Viable System Model (VSM) can be used to determine the necessary and sufficient conditions for the viability of any complex system, in short, to cope with the internal and external variety that the system must handle. Drawing on human neurophysiology, Beer generalized these conditions to apply to organizations from small companies to the social economy of a whole country. The story of his work in Chile for President Salvadore Allende is told in the $2^{\text {nd }}$ edition of Brain of the Firm (Beer, 1981) and is the topic for a documentary film currently being made (Rivera, 2007). One of the model's main characteristics and advantages is that it is scalable, with functions and relationships repeated from the smallest to the most comprehensive levels of recursion in the manner of a series of Russian dolls. Of course, diagnosing or designing a system according to the principles of the VSM is not a guarantee that it will survive. Each system, from the individual organism to the largest collectives is threatened by deficiencies and dangers in their environments. But, it will not fail due to a lack of internal cohesion and communication. With respect to meeting our current challenges, one important thing to remember about the VSM is that, like the human body, all its parts are accepted as belonging to the whole. If the circulatory system is not supplying enough nutrition to a part, that is evidence of a disease, not the results of a narrowly conceived cost benefit analysis.

The recursions of the city, the neighborhood and the household do not address the important question of peace. It belongs to the level of the nation and the community of nations. However, it is a challenge of our times that perceived injustices and grievances held and acted upon by as small a group as a household, or a collection of households much smaller than a neighborhood, may result in acts of violence that have international repercussions. That is, if nothing else, an indication those problems were 
not dealt with at the appropriate scale. It is a caution that illnesses in the body politic that are not treated become septic, as would an untreated wound. Since environmental stress and catastrophe will put additional pressure on longstanding issues, cities and neighborhoods need to reinforce their traditions of equity and fairness. Given the probability of climate change refugees coming to established cities, they will also need to prepare to offer the social support services these people will require to reestablish themselves.

The Viable System Model - with its almost unlimited scope of inclusion - could help us think comprehensively enough to address the changes that must be made and the probable necessity of relocating a substantial proportion of the world's population. At a minimum, it can contribute to the public dialogue needed to accept that success is a possibility and that imaginative alternatives will be required.

\section{The Basics of the VSM for Human Living}

The primary relationship addressed by the VSM is the homeostat between a system and its natural and human environments. All the other functions and communications channels support this relationship; amplifying the actions of the system in the environment and attenuating information and activities in the environment to capture those aspects relevant to the survival and well being or eudemony of the system. Although the system is embedded in the environment, for graphics purposes, the system is depicted as a circle, to indicate its somewhat arbitrary boundary. It is linked with two-way arrows to the environment, shaped like an amoeba to indicate its necessarily fuzzy boundaries.

A system has nowhere else but its environment to look to for whatever it needs. The relationship can be either symbiotic - where system and environment either benefit one another or cause no harm - or it can be parasitic. While parasitic relationships are common, they also come with a built in constraint: if the parasite becomes too demanding, the host does not survive and the parasite dies too, unless it can quickly find another host. Human settlements over the course of history have occasionally had mutually beneficial relationships with their environments, more frequently neutral ones and most frequently, of late, parasitic ones. The current level of demand on our natural environment is such that we are in danger of 'killing' our host - at least for the purposes of human life as we know it. Our long-term viability as a species now requires us to reduce our environmental footprint and to work toward repair and restoration to counteract the damage that has already been done.

The five management functions of the Viable System Model may all be mobilized toward that end.

System(s) One interact directly with the present environment, which includes the social and political environments as well as the natural. In our hunter-gatherer past, the riches of the environment were available through simple human efforts; often, quite literally, picking the low hanging fruit. Now more effort is required so System One has to produce something of value to exchange for what it needs either a product or a service.

There will be more than one of these System One activities so the System Two management function damps their oscillations so that common resources and support services are run smoothly and efficiently.

Some decisions have to be made on the basis of what is best for the whole, which is often different from what is best for a particular part. The System Three management function makes these determinations where the consequences apply more broadly than to a single System One activity. It has a special Three Star function to mop up excess variety and monitor essential variables. 
System Four is concerned with envisioning the future and acting so that threats can be avoided and opportunities seized. System Four holds a model of the system and different models of an anticipated future environment so that it can plan for and test out needed adaptations. Quite often, System Four has a pretty good idea what variety the future has in store for it. At the level of a small business, it involves mapping customer preferences and supplier offerings, keeping abreast of new technologies and training people in new skills and considering recruitment and succession. Many businesses have had to face the fact that their current plant is obsolete, or that there will be a big change in demand for its products. Collectively, we are in a comparable situation: our 'plant' is obsolete and new demands and challenges are on the horizon. Above all, despite the circumstances, System Four is a reservoir of hope.

System Five is the normative management function that brings it all together. Specifically, it monitors the balance between meeting day-to-day requirements and preparing for the future, and embodies the identity and cohesion of the system. This is where the values it chooses are made manifest, and where the biggest current challenge lies. Vision and values must grow quickly to enable us to act comprehensively and to match a desired future. A narrower vision did little harm in the past where actions in one place had little effect on circumstances elsewhere but that time is past and a narrow vision now is delusional and dangerous. In contrast, a robust identity, with a 'can-do' attitude can overcome many seemingly insurmountable obstacles.

\section{The City}

According to the UN Population Fund (United Nations, 2007), 2007 marked the point when more than $50 \%$ of the world's population lived in cities. This proportion is estimated to reach $66 \%$ by 2030 . A big part of reducing our environmental footprint will involve retrofitting and designing cities to support human societies with as little impact on the environment as possible. Added to this challenge is the probability that a number of cities will need to be relocated if sea levels rise as predicted. This means retrofitting many existing cities and building new ones.

\section{Old Cities}

It would do well to remember that cities flourished long before electricity or automobiles. You don't need a car in an old European city with its mostly narrow streets and dense habitation. Nor are elevators needed when few buildings are over five stories tall. Public buildings and gathering places surround multi-purpose central plazas where food markets flourish during the day and coffee shops and performances take over at night. Old cities weren't just about commercial activities. Religion, artistic endeavors and many social networks from kinship to guilds gave structure to people's lives.

Old cities formed particular identities. A visit to the museum of the city of Amsterdam shows a culture that has a trading identity. As a small country, the Netherlands found a niche providing goods to and from the far flung corners of the earth. This contributed to an atmosphere of tolerance - it doesn't do to antagonize your customers and suppliers and it is very helpful to speak their languages. The Dutch have additionally learned a great deal about coping with water both technologically and socially. The polder model of decision making that arose during the Middle Ages to deal with frequent flooding combined listening to everyone's point of view with a commitment to share risks, if necessary, by taking turns getting soaked. (Beatty, 2002) Current versions of the polder model have been criticized for taking too much time (an immanent flood provided a natural closure to discussion) but continue to be applied, such as in the Social Economic Councils that brings together employers, unions and government to adjust this small country's policies to match the variety of the world economy.

\section{New Cities}


I lived in Colombia Maryland, a new city developed by the Rouse Corporation for more than a dozen years. We moved there with three young children, as it seemed to offer the best balance between suburban and downtown living. It was designed around clusters with a school per neighborhood, a village center with shops and a recreation facility and lots of open space connected by bike paths. There were fields for sports and community groups and adult education options were encouraged. Another plus was that it was advertised as a community where all races were welcome.

But, it had a less positive side. The ideal of a mix of income groups was not met. There were not enough jobs for the middle class professionals who bought houses there so they had to commute to Baltimore or Washington, D.C. Most of the people who were needed to staff the stores, restaurants and services couldn't afford to live in Colombia. Although there was some 'subsidized' housing, it attracted NIMBY (not in my backyard) reactions although the people who moved in were predominantly lower middle class. Although there were abundant parks and recreation facilities, there was not much to do and not much welcome for older children and teenagers who were not playing sports or engaged in other organized activities. The communities were not dense enough to support much in the way public transportation, and so there was heavy reliance on the car.

Still, there is knowledge to be distilled from both the experiences of old cities and of the new towns that have been constructed in several countries.

\section{The City's VSM}

Let's look at the city as a Viable System Model. A city's System One operations may be described according to a number of different distinctions. One might divide them into those that produce goods, services and information. Another might be by the provider, whether public, private or non-profit. A third could be by volume of transactions. This distinction would give us food, manufactured goods, communications, utilities, housing, culture, health services, educational services, financial services and so on. As long as each could conceivably earn its keep as a stand-alone system, it can be a System One.

For simplicity's sake, let's take the first of these distinctions - goods, services and information. To provide them, most of the city's System One Units at lower levels of recursion will have to import some of what they need and will find some within the city. This is the first exposure to an environmental footprint. How much can be sourced locally? Where do economies of scale make it less damaging to import from abroad?

What would it take to change this?

Production of food is a good example. New York Magazine (Chamberlain, 2007) featured a proposal by Colombia University Professor Dickson Despommier for vertical farms to be built in New York City. Using the latest technology, one thirty story skyscraper could potentially feed 500,000 New Yorkers and release substantial acreage to be returned to forest. In the market in Toronto, apples, which are produced in Ontario, can be purchased from several continents. There is a contest going on in Toronto as I write to see how many meals can be produced using only what can be obtained within a hundred mile radius of the city. They're facing some challenges, especially with fish. But, many plants that are native to tropical climates, even including tea, coffee and bananas have been grown successfully in greenhouses.

Much of the housing stock in existing cities does not use energy efficiently. While single family homes may invest in energy efficient improvements, many people live in rented accommodation, including those who inhabit the almost 2,000 high rise apartment buildings in Toronto. According to Spears (Spears, 2007) proposals have been made to apply cladding to these buildings, most built before energy 
efficiency was a consideration. A shell of .3 of a meter would be sufficient to install insulation, pipes for gas or geothermal and communication cables. Solar water heating and photovoltaic panels could be installed, balconies enclosed, and the single pane windows replaced. With such improvements, the useful life of these buildings could be extended and their environmental footprint much reduced. The barrier in Toronto is that, unlike many cities in Europe, most of these buildings are privately owned and current law does not allow their improvement to be mandated. Still, tax credits and other incentives might be applied and these buildings, like smaller ones, would enjoy long-term savings.

Manufacturing is another. How many products could be made from recycled materials? Might tastes change to favour handcrafted objects that would be attractive and durable over quickly replaced goods? Could computers and other e-appliances be designed so that they could be upgraded by replacing a small component rather than the whole thing? So, let's think in terms of our goods producing System One operations as primarily transacting with a nearby environment. They will exercise a great deal of autonomy in interacting with their human environments of customers and suppliers.

Service producing System One operations will have an effect on the natural environment in three primary ways. They need products and machinery and energy to perform the services, their employees must travel to work and there will be travel to match the customer and the service. Sustainability may be enhanced by sourcing the products they need as locally as possible and by the employees and customers depending on public transportation, cycling or walking.

Information producing System One operations have the same considerations as service providers, except that much information may be received and sent out electronically minimizing the need for providers and customers to travel. Information providers, as well as some service providers, are not necessarily bound by geography. Data can be sent around the world without distance dependant charges on the environment.

\section{System Two}

The question here is what is needed to keep these System One operations from getting in each other's way and helps them run smoothly. Since there is no 'boss' of these multiple independent entities, the considerations are different from those of different product lines in a single company. The infrastructure that supports these three System One units is a central System Two function. Some of the infrastructure is physical: gas and electricity, telephone wires or towers, roads and other transportation infrastructure, water and sewer services and garbage disposal. These may be provided by either the public sector or the private sector (meaning that some entities will have a dual role as System One businesses providing and being paid for their services and as System Two providers of the indispensable core services used by everyone else). Non-physical infrastructure includes the legal framework including contract and employment law, health and safety regulations and zoning. It also includes more informal mores such as customs, networking facilities and venues for conducting transactions.

Sustainability in the System Two function is concentrated in the activities associated with the physical infrastructure. Experiments are already being done with electricity usage, for example, to charge more for usage at peak times. Transportation infrastructure could favour public transport and bicycles, or road charges could be introduced to offset the impact of the use of private vehicles.

\section{System Three}

Again, there's no 'boss' here, and the autonomy of the System One operations is preserved to the extent that it does not disrupt or constrain other System Ones. The responsibilities for System Three in a city 
often fall on the city government. It makes municipal laws and regulations (and communicates them on the command channel) and engages in resource bargaining to determine what benefits may be expected from what investments in city services or infrastructure and what activities it wants to limit or discourage through increasing taxes or fees. It creates communications channels to listen to the needs and concerns of the various constituencies in the city. System Three in a city has an informal aspect as well, although often at a lower level of recursion, through people of influence in the city, business or professional associations or neighborhood councils. System Three has a responsibility to make sure that no one is treated unfairly and that sacrifices, when they must be made, are shared equitably. This responsibility should be addressed through both formal and informal channels.

System Three Star is essentially an audit function, taking on periodic investigations where a problem may have arisen or to do due diligence. Since the job of System Three Star is to mop excess variety in the system, its activities cannot necessarily be specified in advance except for the required financial audits or health and safety inspections.

\section{System Four}

System Four is concerned with the future. Improving sustainability is a predominantly future oriented activity, whether it is retrofitting an existing city or planning a new one. City officials often travel to other regions to see how they have solved problems. One current example concerns roofs. Dark roofs on buildings absorb heat. Experiments in planting grasses and plants on roofs or painting them white have resulted in energy savings and, in the case of non-air-conditioned buildings, made a contribution toward protecting the health of the residents. Many more ambitious possibilities exist for capturing and reusing gray water, using geothermal energy for heating, pedestrianizing city centres and developing maglev trains for intercity travel. System Four should also investigate measures to mitigate the tendency for wealth and privilege to become concentrated. A combination of public service provisions and the taxes to pay for them will be needed to make the city work for everyone.

The city could sponsor research centres and think tanks devoted to exploring parameters of interaction with other cities and places as well as ways to improve city life. Jane Jacobs (Jacobs, 1984) discussed replacing imports as an important factor in building a successful city, and by extension, a successful country. Although she did not go so far as to recommend an autarkic structure, she did place a high value on city and regional self-sufficiency. The city would also be home to one or more colleges and universities that would both engage in research and prepare people with the knowledge and skills they will need in adult life.

The Three/Four homeostat balances what is necessary to keep the current state of affairs running smoothly with what is needed to adapt to the future. Where this balance point rests depends on circumstances. The results of climate change and other studies have illustrated that too much focus has been on the status quo; and we have built up a deficit that must be made up by increased investment now. It is not that different from a company that has put off new investment for too long. It will need to devote a correspondingly greater level of resources to the future until it has returned to an equilibrium point.

\section{System Five}

System Five is where identity and coherence are focused. If sustainability and fairness are normative goals, then System Five's activities will extend and support them. Too narrow an identity, that does not foster inclusiveness or social justice, will not get everyone to pull together. Too broad a focus (although not a vision) will divert attention away from its own level or recursion to higher levels where it has less influence and, more seriously, leave its own level of recursion under-attended. Because, on the whole, 
cities have tilted more toward maintaining the status quo than to planning to live within their environmental means, normative frameworks must reinforce that changes are necessary, even if they cause some inconvenience or discomfort.

\section{A Look Ahead}

There have been a number of visionaries who have proposed new cities that would go some way to meet these challenges. Here are two:

I had the privilege of being involved with two Syntegrations (Beer, 1994) on the topic of building Old Man River City - the design proposed by a team led by R. Buckminster Fuller for rebuilding the rustbelt city of East St. Louis Illinois (Fuller, 1981). Fuller proposed a torus, or crater shaped city a mile in diameter covered by a geodesic dome. Fifty stories tall, it would house 2,500 sq. ft. apartments on the outer rings with public uses including shops, businesses, schools and recreational facilities located on the inner ones. It would house 125,000 people as well as shops and businesses, with room in the center for gardens, recreational facilities and open space. The dome would protect the building and capture solar energy and rainwater. The goal would be to approach self-sufficiency in energy and water use, as well as recycling almost all waste. Such a design would not need conventional roads and intersections. A network for light rail and golf carts would be built to move goods and accommodate the needs of less mobile people. In addition to its novel architecture, innovative financial instruments would enable residents and employees to own, over time, their apartments and businesses. Fuller designed many structures and posited a world that would work for everyone.

Arcosanti, in Mayer, Arizona, is the built expression of Paulo Soleri's vision. It takes maximum advantage of sun and shade to reduce the need for heating and cooling and is aesthetically very pleasing. Although, designed for 5,000 to 7,000 people, building has been slow, and currently the population fluctuates around 100 people. Soleri has created many ambitious designs for large populations too. Until the Japanese recession, a number of companies were funding a research project to design a city onekilometer square and one kilometer high that would house 100,000 people. Another, called Novanoah, was a design for a floating city. Soleri also suggested using the US Interstate highway system as a solar collector; which could go some way toward powering vehicle transportation.

\section{The Neighborhood}

The next recursion level of the VSM will be a neighborhood, such as a geographically compact community of about 5,000 where people can conveniently walk to their destinations. This is a number that can reasonably be expected to know, at least by sight, a majority of the inhabitants. Although actual percentages vary widely, a typical Toronto population of this size might include (roughly) 1,000 children and young people from 0 to 17, about 700 from 18-24, a working age population of 2,800 and an over 65 population of 500. At this scale, a nursery and elementary school could be supported and a secondary school shared with a contiguous neighborhood.

A sustainable neighborhood would include System One operations representing the goods and services available locally including businesses, non-profits and some public entities. Examples would include its residential stock, food and convenience stores, restaurants, dry cleaners, real estate agencies, bank branches and retail shops. On the public/non-profit side we would expect to see an elementary school, parks, a community recreational facility, a branch library, a postal outlet and some charity shops. In addition to providing for most routine transactions to be possible without a car, this type of neighborhood also fosters social interactions and safety. It is alive from the early morning customers at 
the coffee shops to the late evening crowd at the restaurants and pubs.

The neighborhood may also have some facilities that attract a wider population of city or region, such as a hospital, a hotel, a specialty shop or a well-known restaurant. Note that it would be almost impossible for a neighborhood to be sustainable if it has no commercial activity. Ideally most of the people who are employed in the neighborhood could also live there, or not far away.

System Two for a neighborhood would derive from the city but might include zoning, style requirements for signage, parking regulations and the like. Coordination of common spaces would probably be handled at the level of the facility, mostly on a first come/first served basis. Informal standards might apply to noise, upkeep of front gardens and similar matters.

System Three involves decisions taken on behalf of the whole. In some cases such decisions would involve advisory neighborhood commissions that would make recommendations to city hall, in others, informal communications with the local councilor and ad hoc committees. Improvements to the street or a local park, a new traffic light, compost offerings, clean-up days are examples. System Three at the neighborhood level would also have or share representation in the city council. System Three Star would mostly happen through the municipal government although requests could be triggered at the neighborhood level, for example to deal with a trouble spot.

System Four happens in cooperation with the city government. Surveys, public meetings and hearings and commissioned studies are undertaken to provide information specific to that neighborhood and its particular needs and concerns. On a less formal level, a handful of citizens can form a committee to advocate for action on a problem they have identified or an opportunity that they see. They also will bring back information from their travels on what they might adopt from other neighborhoods. System Four might also be considering how to incorporate new System Ones such as an influx of new people to the neighborhood.

System Five in a neighborhood represents its identity and norms. Some neighborhoods have a unique identity based on many years of history, ethnic make-up or a particular facility or industry that has dominated its economic life. Other identities are formed by the connections formed among the people who live there but are not remarkable in other ways. Both types of identity could work in common to achieve sustainability goals if enough of their members were convinced it was important.

\section{The Household}

For the purposes of the model, a household will be considered to be the people occupying a dwelling with some autonomy over their use of resources. They could be anything from a nuclear family to roommates to a single person. What they have in common is an element of choice in acting a more sustainable way.

The System One operations of a household are the activities that the members do to maintain themselves as viable systems. They will be or have been engaged in activities that bring in a financial income and may also engage in activities that obtain other rewards such as volunteer work, sports or hobbies.

Most actions to promote sustainability at the household level are small, although many small decisions can have a large effect. Individually, members themselves can make many choices about what to consider when making purchases, how to get around the city, and how to reduce energy or peak demand use at home and at work. They may also become active in civic affairs and put forward their points of view in neighborhood or city forums. 
System Two functions include all the ways that they coordinate their activities. A thermostat is an example of an active regulator. Once a temperature has been decided upon, the furnace or air conditioner is turned on or off to maintain that temperature. This is also a typical focus for energy saving - keeping it several degrees cooler or warmer saves energy. Installing motion sensitive lights over the outside doors is another. Habits of the house - such as not leaving the lights on or avoiding the use of non-rechargable batteries also play a part in System Two. System Two might also support the donation for reuse of anything no longer needed by its members.

System Three is engaged in making decisions about the use of resources that they have agreed should be distributed according to the needs of the collective. Conversations might be held to make decisions about the use of a car that is shared by more than one person. Purchasing choices for the household might lean toward buying bulk products with less packaging, replacing chemical cleaners with more natural products, using refillable containers and bringing canvas bags to the grocery store. Although the actions would be those of individuals, in a household, decisions could be made about ways to support volunteer work in social or environmental causes.

System Four for the household could be looking for new ways to decrease its environmental footprint. Replacing an old appliance with an energy efficient model, installing a green roof or upgrading the insulation are concrete ways to reduce energy use. A decision could also be made to install solar or wind generation capability to reduce demand on the grid and have a back-up in case of a black-out On an informational front, making an effort to become informed and active as citizens also makes a contribution.

System Five represents the identity of the household. If its norms include a strong commitment to environmental sustainability, its members will be reinforced as they make large and small decisions that have an impact on the environment. Changes that will need to be made - either learning to live with less or learning to live in communities that have grown huge with the addition of climate change refugees take place on an internal level although they are expressed externally.

\section{Conclusions}

\section{A Possible Future}

It has become commonplace to talk about alternative futures, yet there is value in serious consideration of what they might be. For example, the current issue of Toronto Life presents a sobering view of what the city might look like in forty years if climate change is not addressed at a level more substantial than any so far advanced - a 90\% reduction by 2030 (Grady, 2007). The environment is a whole system, subject to knock-on effects. A hotter climate brings changes in weather patterns from a steady incidence of rainfall to one of alternating drought and monsoon. Less even rainfall means leads to less and less reliable hydro-electric power, which leads to brown and black-outs and higher energy prices, which leads to using more fossil fuel which leads to more air pollution and more asthma and other respiratory illnesses. Even with temperatures over thirty the norm, Toronto would still be a magnet for people for people from hotter climates. Many would arrive without skills to earn a living wage and would further exacerbate the divisions between the haves (who might be expected to retreat to guarded and gated communities) and the have-nots. Democracy itself will be under threat under these circumstances.

\section{Changing Minds}

This does not have to be the future in store for us. If people really understand the seriousness of the 
environmental issue, commitments will be mobilized and action will be taken. We have been living beyond our environmental means for too long for the adjustments to be without discomfort. But, if discomfort is shared, people will pull together and meet the threat.

An important part of sharing the work and hard choices that have to be made is for there to be sufficient dialogue for people to believe that their interests have been understood and considered. Group processes, including but not limited to Beer's Team Syntegrity process, will be key to meeting this need. There will be too many decisions that have to be made to rely on horse and buggy era meeting and dialogue formats.

We have a great deal of information already about the future that is in store for us if we carry on as usual, and even if we take as many steps as possible now. A great deal will depend on the social bedrock on which the scientific and technical decisions will be made. A strong social aspect, based on fairness and maximum autonomy will enable forward motion and help to preserve democracy.

\section{References}

Beatty, D. (2002) Personal Communication. Delft, The Netherlands

Beer, S. (1981) Brain of the Firm, $2^{\text {nd }}$ ed. Chichester: John Wiley \& Sons.

Beer, S. (1994) Beyond Dispute: the Invention of Team Syntegrity. Chichester, John Wiley \& Sons.

Chamberlain, L. (2007) 'Skyfarming' in New York Magazine, April 9.

Fuller, R.B. and Kuromiya, K. (1981) Critical Path. New York: St. Martin’s Pre ss.

Grady, W. (2007) 'Boiling Point' in Toronto Life, June pp. 86-92.

Jacobs, J. (1984) Cities and the Wealth of Nations. New York: Random House.

Soleri, P. (2007) www.arcosanti.org/archives/originaldrawings/arcology/main.html.

Spears, J. (2007) 'Concrete Slab Apartments Gain New Life with Retrofits'. Toronto Star, May 31, P.

A12.

United Nations Population Fund (2007) www.unfpa.org 